\title{
Oral Glucose Augmentation of Insulin Secretion
}

\author{
INTERACTIONS OF GASTRIC INHIBITORY POLYPEPTIDE WITH
}

AMBIENT GLUCOSE AND INSULIN LEVELS

\author{
Dana K. Andersen, Dariush Elahi, John C. Brown, Jordan D. Tobin, ANd Reubin \\ ANDRES, Clinical Physiology Branch, Gerontology Research Center, National \\ Institute on Aging, National Institutes of Health, U. S. Public Health Service, U. S. \\ Department of Health, Education, and Welfare, Bethesda and Baltimore City \\ Hospitals, Baltimore, Maryland 21224, and Department of Physiology, University \\ of British Columbia, Vancouver, British Columbia, Canada V6T 1W5
}

A B S T R A C T Gastric inhibitory polypeptide, or GIP, has been postulated as the major enteric hormonal mediator of insulin release. The release of immunoreactive GIP (IR-GIP) after oral glucose and its role in insulin release was studied in normal men by the glucose clamp technique. In 24 subjects studied with the hyperglycemic clamp, blood glucose was maintained at $125 \mathrm{mg} / \mathrm{dl}$ above basal for $2 \mathrm{~h}$ via a primedcontinuous IV glucose infusion coupled to a servo-controlled negative feedback system. $40 \mathrm{~g}$ glucose per $\mathrm{m}^{2}$ surface area was ingested at $60 \mathrm{~min}$, and the blood glucose was maintained at the steady-state hyperglycemic level. Plasma IR-GIP and insulin (IRI) levels were measured throughout the 2 -h period. IR-GIP levels changed little when IV glucose alone was given; the mean basal value was $305 \pm 34$ (SEM) pg/ml. After oral glucose, IR-GIP levels began to rise within $10 \mathrm{~min}$ and reached a peak within $40 \mathrm{~min}$ of $752 \pm 105$ $\mathrm{pg} / \mathrm{ml}$. Plasma IRI responded initially to the square wave of hyperglycemia in the typical biphasic pattern. After oral glucose, plasma IRI levels rose strikingly above the elevated levels produced by hyperglycemia alone, reaching a peak of $170 \pm 15 \mu \mathrm{U} / \mathrm{ml}$ within 45 min. The time course of the rise in IR-GIP and IRI was nearly identical.

To assess whether the maintenance of euglycemia would affect this process, the euglycemic clamp was

This work was presented in part at the Eastern Section Meeting of the American Federation for Clinical Research, Boston, Mass., 9 January 1976, and in part at the National Meeting of the American Society for Clinical Investigation, Atlantic City, N. J., 2 May 1976.

Dr. Andersen's present address is Department of Surgery,

Duke University Medical Center, Durham, N. C. 27710.

Received for publication 3 December 1976 and in revised form 9 March 1978. employed in 11 subjects to maintain basal blood glucose levels during a similar 2-h study. A primedcontinuous insulin infusion, with a constant rate of $120 \mathrm{mU} / \mathrm{m}^{2}$ per min was given together with a servocontrolled glucose infusion. This resulted in hyperinsulinemia of $\sim 300 \mu \mathrm{U} / \mathrm{ml}$. Glucose was ingested by six subjects at $60 \mathrm{~min}$. Plasma IR-GIP responded to oral glucose similarly to the effect seen in the hyperglycemic studies. No increase in endogenous insulin release was seen despite the increase in IR-GIP when euglycemia was maintained. However, in five of seven subjects given insulin whose blood glucose concentration rose by $20 \mathrm{mg} / \mathrm{dl}$ or more after oral glucose, there was an increase in plasma insulin concentration associated with the elevation in IR-GIP. Thus, the effect of glucose-released IR-GIP on insulin secretion is dependent upon the presence of some degree of hyperglycemia and is not inhibited in the presence of marked hyperinsulinemia.

\section{INTRODUCTION}

It has long been considered that gastrointestinal substances modify glucose metabolism (1). After the development of techniques to measure serum insulin (2), the ability to study the possible role of gut hormones in controlling insulin secretion was greatly increased. In 1964 McIntyre et al. reported that the insulin response to oral glucose was greater than to glucose given intravenously (3). This was confirmed by Perley and Kipnis (4) among others, and further studies suggested that this effect was produced by gastrointestinal hormone(s) $(5,6)$. Although many studies have been conducted on the specific identity of such a hormonal mediator, the issue has remained open to investigation (7). Recently, the isolation of gastric inhibitory 
polypeptide (GIP) ${ }^{1}$ by Brown et al. (8) and the demonstration that infusion of this peptide augments glucosestimulated insulin release without itself being an insulin secretagogue (9) has raised speculation that this may be the gastrointestinal mediator of insulin release. In addition, increases in circulating levels of GIP after the ingestion of nutrients associated with insulin release, notably glucose $(10-13)$ and fat $(14,15)$, provide further evidence for the association of GIP with insulin release.

In this study the glucose clamp technique $(16,17)$ has been adapted to determine the response of immunoreactive GIP (IR-GIP) to oral glucose, the effect of circulating glucose and insulin levels on GIP secretion, and the response of elevated GIP levels on insulin production. In essence, this technique allows the separation of the effects of circulating IR-GIP and of glucose levels on insulin secretion. Endogenous GIP secretion was stimulated by an oral glucose load under the following conditions: $(a)$ after the establishment of steady-state hyperglycemia by the servo-controlled intravenous infusion of a glucose solution and $(b)$ after the establishment of a hyperinsulinized state with the maintenance of euglycemia by a fixed insulin infusion and a servo-controlled glucose infusion. In both cases the ingestion of glucose was not permitted to change the established glycemic state but did result in secretion of GIP. Both the change in circulating level of GIP and its effect on insulin secretion can then be assessed in the absence of changes in the blood glucose level. Plasma IR-GIP and insulin (IRI) were measured during these conditions, and comparisons were made before and after the ingestion of a standard oral glucose dose.

\section{METHODS}

\section{Patient selection and preparation}

78 studies were made on 77 ambulatory, healthy male volunteers. 54 subjects were community dwelling participants in the Baltimore Longitudinal Study of Aging. This group was supplemented by 17 students and hospital employees and by 6 ambulatory, middle-aged or elderly subjects who were residents on a research ward. Subjects were randomly assigned to hyperglycemic or euglycemic study protocols; the age range for 52 individuals studied with the hyperglycemic protocol was $18-92 \mathrm{yr}$, with a median age of 51 . The age range for 26 subjects studied with the insulin infusion protocol was $22-75 \mathrm{yr}$, with a median age of 43 . All subjects were within $20 \%$ of their desirable body weight, as determined by the mean of the weight range for male subjects of medium frame from the 1959 Metropolitan Life Insurance Co. table of desirable weight, and all were consuming weight maintaining diets of normal composition. All had negative

${ }^{1}$ Abbreviations used in this paper: CV, coefficient of variation; GIP, gastric inhibitory polypeptide; IR-GIP, immunoreactive gastric inhibitory polypeptide; IRI, immunoreactive insulin. first degree family histories for diabetes mellitus and none had elevated fasting blood sugars. All subjects had previously received an oral glucose tolerance test $(1.75 \mathrm{~g} / \mathrm{kg}$ body $w \mathrm{t})$ or an intravenous glucose tolerance test $(0.375 \mathrm{~g} / \mathrm{kg}$ body wt in $5 \mathrm{~min}$ ) or both, and were considered normal by an ageadjusted nomogram (18). Subjects were fasted $12 \mathrm{~h}$ overnight before testing. All subjects were advised of the nature and effects of the study and informed consent was obtained.

\section{Experimental protocol}

To assess endogenous GIP responses to oral glucose while controlling the blood glucose concentration, we performed two types of glucose clamp studies. Basically, conditions were created that required the infusion of a relatively large amount of glucose intravenously. Thus, when glucose is ingested, the desired blood glucose level can be maintained by appropriate reduction in the intravenous glucose infusion to compensate for the glucose absorbed via the gastrointestinal tract.

In all types of experiments the following procedure was used. An antecubital intravenous polyethylene catheter was inserted for infusion of glucose with or without insulin as described below. A second polyethylene catheter was inserted retrogradely into a dorsal hand or wrist vein, and the hand was enclosed in an insulated, grounded chamber warmed to $68^{\circ} \mathrm{C}$ to "arterialize" the venous blood obtained for all samples (19). After allowing temperature equilibration, at least three control blood samples were obtained at $10-\mathrm{min}$ intervals and immediately assayed for blood glucose. Heparinized blood samples were quickly centrifuged at $4^{\circ} \mathrm{C}$; aliquot samples were frozen for subsequent insulin and GIP assay. In all experiments, samples for blood glucose, plasma IR-GIP, and plasma IRI, were obtained every $2 \mathrm{~min}$ for $10 \mathrm{~min}$, and then every $5 \mathrm{~min}$ for the duration of the study $(2 \mathrm{~h})$. The blood glucose was maintained at the preselected value for $120 \mathrm{~min}$ by a servocontrolled negative feedback system coupled to a variable speed infusion pump (Harvard Apparatus Co., Millis, Mass.) delivering a $20 \%$ glucose solution.

\section{HYPERGLYCEMIC STUDIES $(n=52)$}

At $0 \mathrm{~min}$, a logarithmically falling, priming infusion of glucose was administered over a 12 -min period to raise the blood glucose rapidly to a level of $125 \mathrm{mg} / \mathrm{dl}$ above basal.

Studies with oral glucose. At $60 \mathrm{~min}, 24$ subjects ingested $40 \mathrm{~g}$ glucose $/ \mathrm{m}^{2}$ surface area within $5 \mathrm{~min}$. The blood glucose level was maintained constant after oral glucose by appropriate reduction in the intravenous glucose infusion to compensate for enteric glucose absorption. Mean blood glucose for the entire study period was maintained at an average of $98 \pm 1.7 \%$ (SD) of the desired goal. The coefficient of variation of the glucose concentration during the 2 -h period averaged $4.3 \pm 0.8 \%$ (SD).

Studies without oral glucose. In 28 other subjects, not reported in detail in this paper, intravenous glucose only was given over the 2 -h period. The subjects were comparable in age and obesity to the subjects who received oral glucose. Mean blood glucose for the entire study period was maintained at an average of $99.9 \pm 2.2 \%$ of the desired goal. The coefficient of variation of the glucose concentration during the 2 -h period averaged $3.5 \pm 1.0 \%$.

\section{INSULIN INFUSION STUDIES $(n=26)$}

At $0 \mathrm{~min}$, a logarithmically falling, priming dose of insulin (Iletin, pork insulin, Eli Lilly \& Co., Indianapolis, Ind.) 
$\left(2,400 \mathrm{mU} / \mathrm{m}^{2}\right)$ was administered over a period of $10 \mathrm{~min}$ via the antecubital vein; for the next $110 \mathrm{~min}$, insulin was infused at a constant rate of $120 \mathrm{mU} / \mathrm{m}^{2}$ per min. To prevent insulin adsorption to glassware and to the plastic infusion apparatus, infusates were prepared with the addition of $2 \mathrm{ml}$ of the subject's whole blood per $50 \mathrm{ml}$ of infusate. Insulin recovery in the infusates averaged $104 \pm 9 \%$. At $4 \mathrm{~min}$, an intravenous $20 \%$ glucose infusion was begun. Appropriate corrections in the glucose infusion rate were made every 5 min to maintain the blood glucose concentration at the desired level.

Insulin infusion with euglycemia $(n=11)$. In these studies, the blood glucose was maintained at the fasting level for the duration of the experiment.

(a) Studies with oral glucose. At $60 \mathrm{~min}$, six subjects ingested $40 \mathrm{~g}$ glucose $/ \mathrm{m}^{2}$ surface area within $5 \mathrm{~min}$. The mean blood glucose concentration was maintained at $97 \pm 1.2 \%$ of the basal levels (coefficient of variation $6.1 \pm 1.2 \%$ ) by means of appropriate reduction in the intravenous glucose infusion in the 2 nd $h$.

(b) Studies without oral glucose. In five other subjects, no oral glucose was administered. The mean blood glucose concentration was maintained at $99 \pm 0.6 \%$ of the fasting level for the 120 -min period (coefficient of variation $3.6 \pm 0.8 \%$ ).

Insulin infusion with hyperglycemia during the 2nd $h$ $(n=15)$. In these studies, at $60 \mathrm{~min}$ the blood glucose was allowed to increase gradually above the basal level and was maintained at a plateau from 90 to $120 \mathrm{~min}$.

(a) Studies with oral glucose. At $60 \mathrm{~min}, 12$ subjects ingested $40 \mathrm{~g}$ glucose $/ \mathrm{m}^{2}$ surface area within $5 \mathrm{~min}$. The $90-120$ min plateau glucose concentrations ranged from 8 to $61 \mathrm{mg} / \mathrm{dl}$ above the basal glucose levels.

(b) Sudies without oral glucose. In three subjects, blood glucose concentration during the $90-120-\mathrm{min}$ period was raised by 27,29 , and $45 \mathrm{mg} / \mathrm{dl}$ above the basal glucose by an appropriate increase in the intravenous glucose infusion.

\section{Chemical analyses}

Blood glucose concentrations were measured by the AutoAnalyzer ferricyanide reduction procedure (Technicon Instruments Corp., Tarrytown, N. Y.), modified to provide determination of values in $4 \mathrm{~min}$ from the time of sampling. Plasma was assayed for insulin in duplicate by the double antibody radioimmunoassay technique (20).

Plasma GIP was measured by a single antibody radioimmunoassay utilizing dextran-charcoal separation of bound and free hormone (21). The lower limit of detection was $125 \mathrm{pg} / \mathrm{ml}$. In 2 of the 50 studies, the basal GIP level was below this limit; in these 2 cases, the detection limit was assigned as the basal value. The between-assay variance can be expressed as the coefficient of variation (CV) of 27 separate runs on a pooled plasma sample over a 2 -yr period. The CV of this sample was $12.8 \%$. This sample was in the mid-range of the standard curve. In the routine plasma analyses, samples were run in duplicate. Plasma samples were coded before GIP assay; the code was not broken until the assay results were reported.

\section{Statistical methods}

The hormone concentration curves for each type of study were compared for the periods before and after glucose ingestion (paired $t$ test) and between means of groups studied under similar circumstances with and without oral glucose ingestion (unpaired $t$ test). The mean concentrations of each 30 -min period were calculated for comparison of intervals.

\section{RESULTS}

Hyperglycemic clamp studies. Fig. 1 shows the blood glucose, plasma insulin, plasma GIP, and glucose infusion curves in the 24 subjects who received hyperglycemic clamps with oral glucose at $1 \mathrm{~h}$. Plasma IRI rose from a basal value of $7.9 \pm 0.7($ mean \pm SEM) to a peak of $54.1 \pm 3.9 \mu \mathrm{U} / \mathrm{ml}$ at $4 \mathrm{~min}$ in response to the hyperglycemia. After its fall to a nadir of $31.1 \pm 2.4$ $\mu \mathrm{U} / \mathrm{ml}$ at $20 \mathrm{~min}$, the IRI rose steadily; the mean value for the $30-60-\mathrm{min}$ period was $40.6 \pm 3.1 \mu \mathrm{U} / \mathrm{ml}$. After oral glucose at $60 \mathrm{~min}$, the mean plasma IRI curve began to rise at $70 \mathrm{~min}$, was clearly elevated at $75 \mathrm{~min}$, and peaked at $170.5 \pm 14.6 \mu \mathrm{U} / \mathrm{ml}$ at $105 \mathrm{~min}$. The mean plasma IRI for the $90-120$-min period was $165.9 \pm 12.5 \mu \mathrm{U} / \mathrm{ml}$.

The anticipated 90-120-min IRI concentration, had oral glucose not been given, can be computed in these subjects from data obtained in a series of 28 hyperglycemic clamp studies in which oral glucose was not given. From these data, the relation between the $30-60-\mathrm{min}$ and the $90-120-\mathrm{min}$ IRI was computed: IRI $_{90-120}=11+1.40\left(\mathrm{IRI}_{30-60}\right)$. The coefficient of correlation $(r)$ is 0.908 . The coefficient of variation of the predicted $90-120-\mathrm{min}$ value is $17.4 \%$.

The mean predicted $90-120$-min value for the 24 subjects is $67.2 \pm 4.3 \mu \mathrm{U} / \mathrm{ml}$. The mean difference between the predicted values and the actual IRI values achieved in the 24 subjects on the hyperglycemia + oral glucose protocol is $98.6 \pm 10.1 \mu \mathrm{U} / \mathrm{ml}$ $(P<0.001)$. Each of the 24 subjects had a higher 90-120-min IRI than predicted, the range being 6-216 $\mu \mathrm{U} / \mathrm{ml}$. The ratio of actual to predicted insulin levels at $90-120 \mathrm{~min}$ is $2.50 \pm 0.16$.

After the initial priming infusion of glucose, the infusion rate remained quite constant from 12 to $60 \mathrm{~min}$. Note that despite the glucose ingestion at $60 \mathrm{~min}$, it was still necessary, on the average, to maintain the glucose infusion essentially unchanged for the next $30 \mathrm{~min}$ (from 60 to $90 \mathrm{~min}$ ). In some subjects the glucose infusion had to be sharply reduced to compensate for the glucose influx from the gut; in others, the need for infused glucose actually increased in the 60-90min period in response to the rise in insulin. After $90 \mathrm{~min}$, the mean glucose infusion rate rose so that by the end of the 2 -h infusion, the rate essentially doubled.

The mean basal plasma IR-GIP level was $305 \pm 34$ $\mathrm{pg} / \mathrm{ml}$. The basal GIP values reported in the literature are very variable. Mean values range from 85 to 410 $\mathrm{pg} / \mathrm{ml}(10,12,13,21-27)$ in normal subjects. Assay differences as well as differences in the populations sampled undoubtedly contribute to this variance.

Basal IR-GIP levels did not change significantly during the intravenous glucose infusion (Table I). Although the mean 0-30- and 30-60-min GIP levels for 


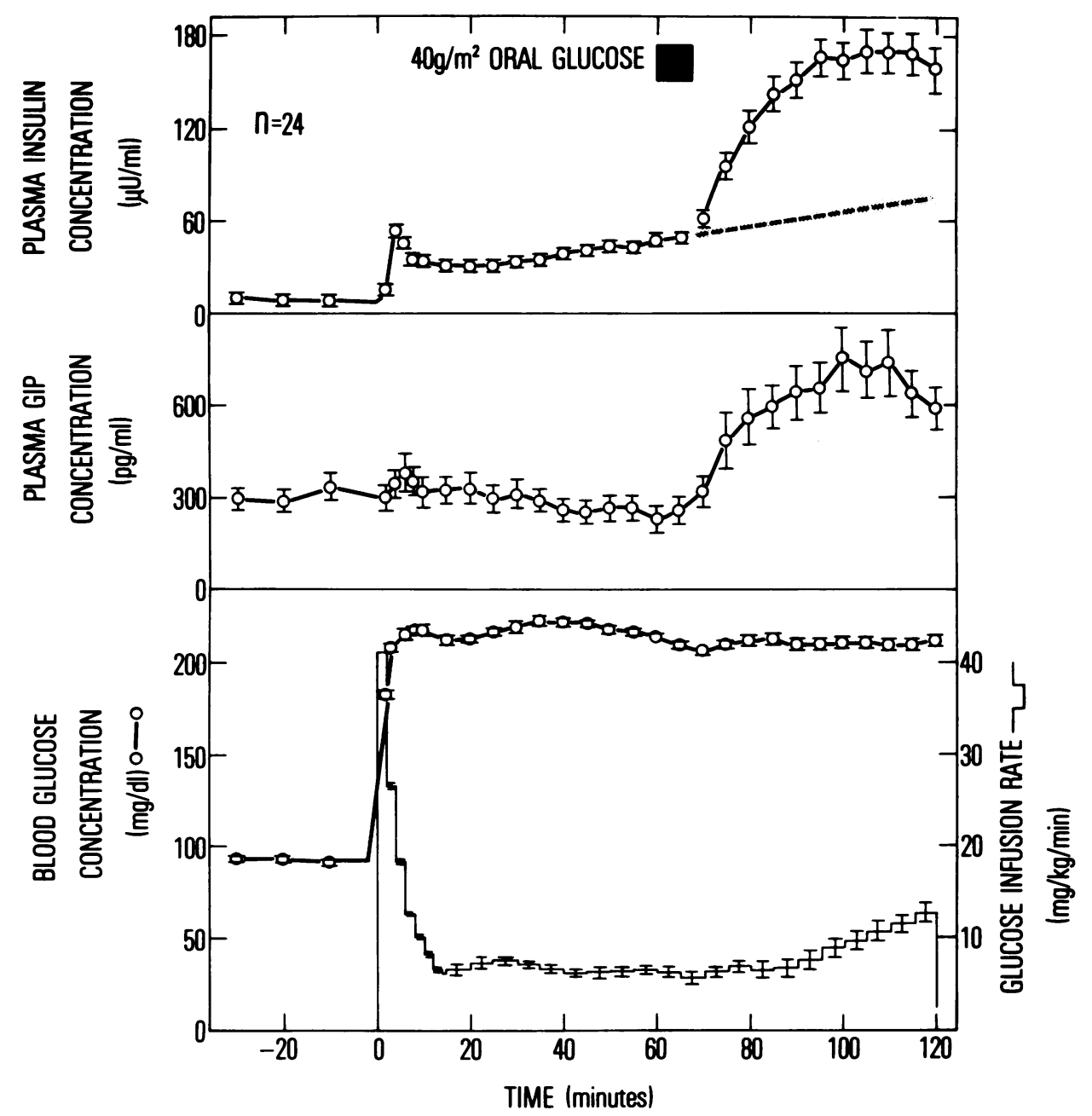

FIGURE 1 Hyperglycemic clamp with oral glucose. Plasma insulin, plasma GIP, and blood glucose concentrations are shown for 24 subjects. The means \pm SEM are shown. The dashed line represents the expected plasma insulin concentration for these subjects had oral glucose not been given (see text); the shaded area represents \pm 1 SEM.

the 24 subjects did not differ significantly from the basal values, there was considerable fluctuation in the measured GIP values during these times in individual subjects. The magnitude of this variance can be appreciated from the $\mathrm{CV}$ of the 30-60-min GIP levels. The CV ranged from 0 to $82 \%$ and averaged $39 \pm 20 \%$ (SD). Thus, in an individual subject, it may not be possible to detect the exact moment of increase in GIP after glucose ingestion at $60 \mathrm{~min}$. But one can have great confidence in the results from the entire group (Fig. 1). Similar to the mean plasma insulin response, mean plasma IR-GIP began to rise at $70 \mathrm{~min}$ and was clearly elevated at $75 \mathrm{~min}$. The highest mean GIP value occurred at $100 \mathrm{~min}, 752 \pm 105 \mathrm{pg} / \mathrm{ml}$. The range of the peak level (regardless of time) was 400$2,300 \mathrm{pg} / \mathrm{ml}$, with a mean of $1,094 \pm 109 \mathrm{pg} / \mathrm{ml}$. Each subject showed a higher mean GIP value at 90-120 min than at $0-60 \mathrm{~min}$; the increases ranged from 56 to $1,130 \mathrm{pg} / \mathrm{ml}$, with a mean of $392 \pm 60 \mathrm{pg} / \mathrm{ml}(P<0.001)$.

It can be seen from the figure that the time course of the elevation in IR-GIP after oral glucose is nearly identical with the time course of the augmented insulin response after $60 \mathrm{~min}$. We have also examined the relation between the plasma IR-GIP and IRI curves in the 24 individual subjects. Because of the fluctuations in IR-GIP levels as noted above, it is difficult to delineate with precision the time of the earliest increase in its concentration. Still, in 16 of the 24 subjects, the first detectable increases in both hormones occurred within \pm 5 min of each other and in 22 of the 24 within $\pm 10 \mathrm{~min}$. In the other two subjects, IR-GIP levels were below the assay detection limit during the $30-60-\mathrm{min}$ time period so that increases in IR-GIP could have occurred well before 
TABLE I

Plasma IR-GIP: Effect of Oral Glucose

\begin{tabular}{cccc}
\hline & $\begin{array}{c}\text { (A) Hyper- } \\
\text { glycemia } \\
\text { study }\end{array}$ & $\begin{array}{c}\text { (B) Insulin } \\
\text { infusion } \\
\text { study with } \\
\text { euglycemia }\end{array}$ & $\begin{array}{c}\text { (C) Insulin } \\
\text { infusion } \\
\text { study with } \\
\text { hyperglycemia }\end{array}$ \\
\hline min & & $p g / m l$ & \\
& $(24)^{*}$ & $(6)$ & $(10)$ \\
Basal & $305 \pm 34 \ddagger$ & $402 \pm 97$ & $402 \pm 72$ \\
$0-30$ & $324 \pm 38$ & $351 \pm 82$ & $320 \pm 49$ \\
$30-60$ & $267 \pm 35$ & $314 \pm 52$ & $286 \pm 39$ \\
& & & \\
& Glucose ingested at 60 min & \\
$60-90$ & $444 \pm 61$ & $635 \pm 144$ & $860 \pm 135 \S$ \\
$90-120$ & $687 \pm 74$ & $1,010 \pm 204$ & $1,600 \pm 293 \S$ \\
$([90-120]-[0-60])$ & $392 \pm 60$ & $678 \pm 181$ & $1,296 \pm 278 \S$ \\
\hline
\end{tabular}

* Number of subjects.

† Mean \pm SEM.

$\S$ Significantly different from the hyperglycemia study at the $P<0.01$ level. we could detect it. These are the only two subjects who showed IRI increases well before IR-GIP levels could be detected. It is important that in none of the 24 subjects did IR-GIP levels begin to rise more than 10 min before IRI levels increased.

Insulin infusion studies with euglycemia $(n=11)$. These studies were designed to examine the role of the prevailing blood glucose level on the insulinotropic effect of IR-GIP. Figs. 2 and 3 illustrate the results of five euglycemic clamp studies performed without oral glucose, and six studies in which glucose was ingested at $60 \mathrm{~min}$. The exogenous insulin infusion in both groups resulted in plasma IRI elevations to nearly 400 $\mu \mathrm{U} / \mathrm{ml}$ within $10 \mathrm{~min}$, with a stable plateau of $\sim 300$ $\mu \mathrm{U} / \mathrm{ml}$ reached by $30 \mathrm{~min}$. The glucose infusion required to maintain euglycemia increased rapidly and approached a plateau by $60 \mathrm{~min}$ in those studies performed without oral glucose. In the six subjects who ingested glucose at $60 \mathrm{~min}$, a sharp reduction in the intravenous glucose infusion was necessary to maintain euglycemia in the 2 nd $h$, i.e., during glucose absorption (Fig. 2). Plasma IR-GIP (Fig. 3 and Table I) increased

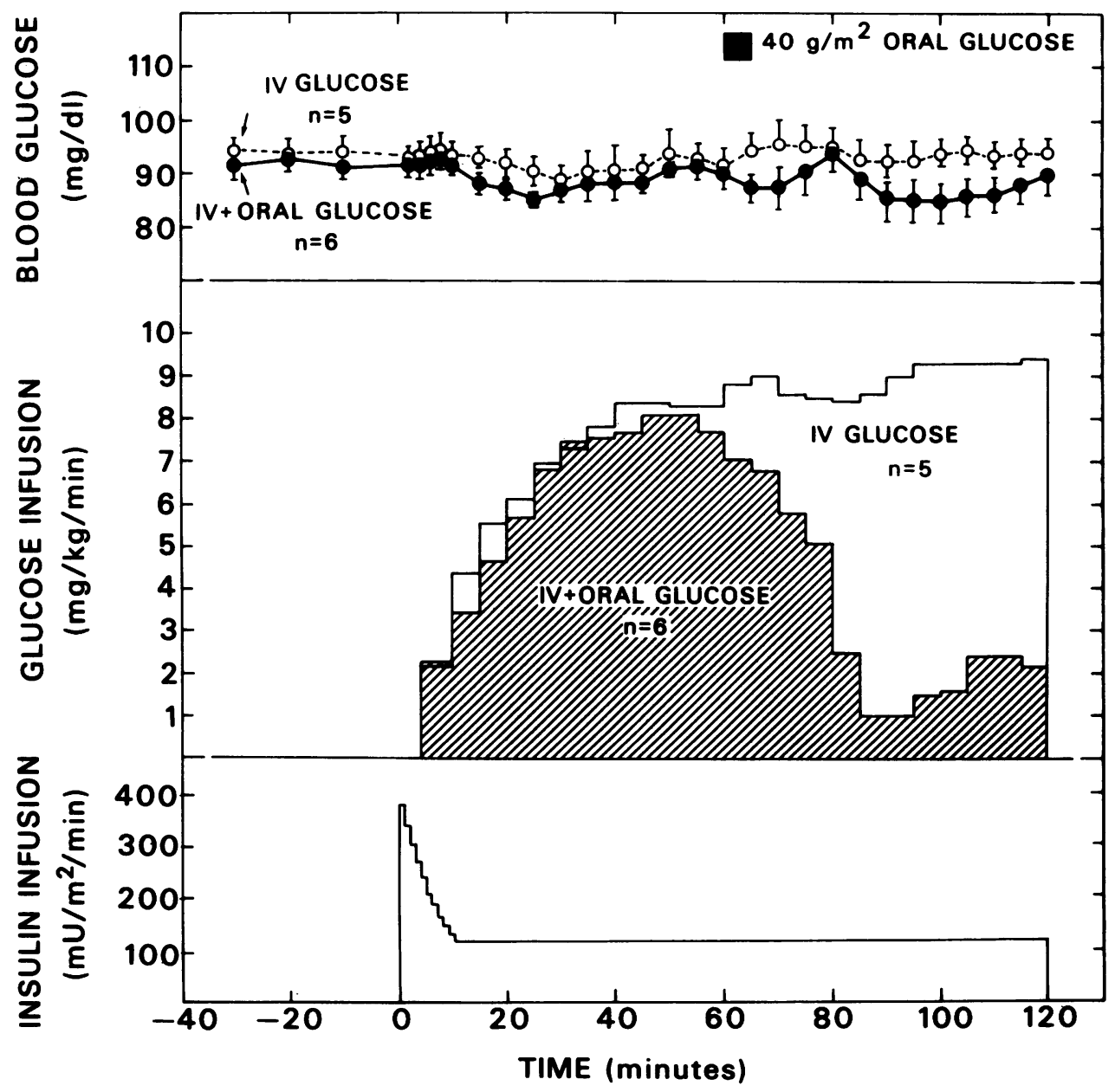




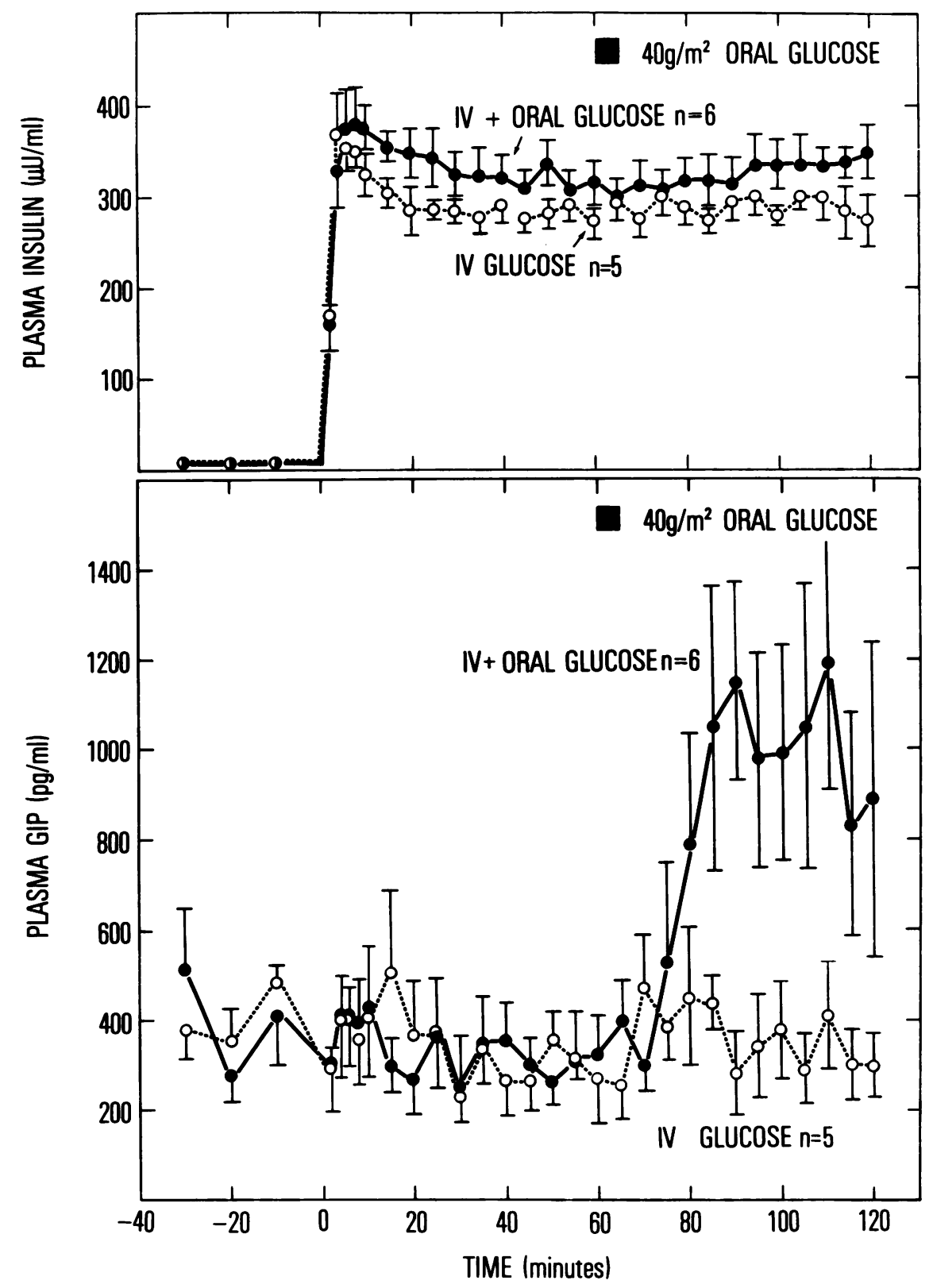

FIgURE 3 Insulin infusion studies. Plasma insulin and GIP responses are shown for five subjects who received IV glucose only and for six subjects who, in addition, ingested glucose at $60 \mathrm{~min}$. Means $\pm \mathrm{SEM}$ are shown.

significantly after oral glucose. The increases ranged from 133 to $1,255 \mathrm{pg} / \mathrm{ml}(90-120$ minus $0-60 \mathrm{~min})$; the mean increase was $678 \pm 181 \mathrm{pg} / \mathrm{ml}(P<0.02)$ under these conditions of euglycemia and hyperinsulinemia. Insulin infusion studies with hyperglycemia $(n=15)$.
To determine whether endogenous insulin release could be evoked by endogenous GIP during an exogenous insulin infusion, the blood glucose concentration was allowed to increase gradually after 60 min. The blood glucose was maintained at a plateau

FIGURE 2 Insulin infusion studies with euglycemia. The insulin infusion, the glucose infusion required to maintain euglycemia, and the blood glucose levels are shown for five subjects who received IV glucose only and for six subjects who, in addition, ingested glucose at $60 \mathrm{~min}$. Means \pm SEM are shown. 


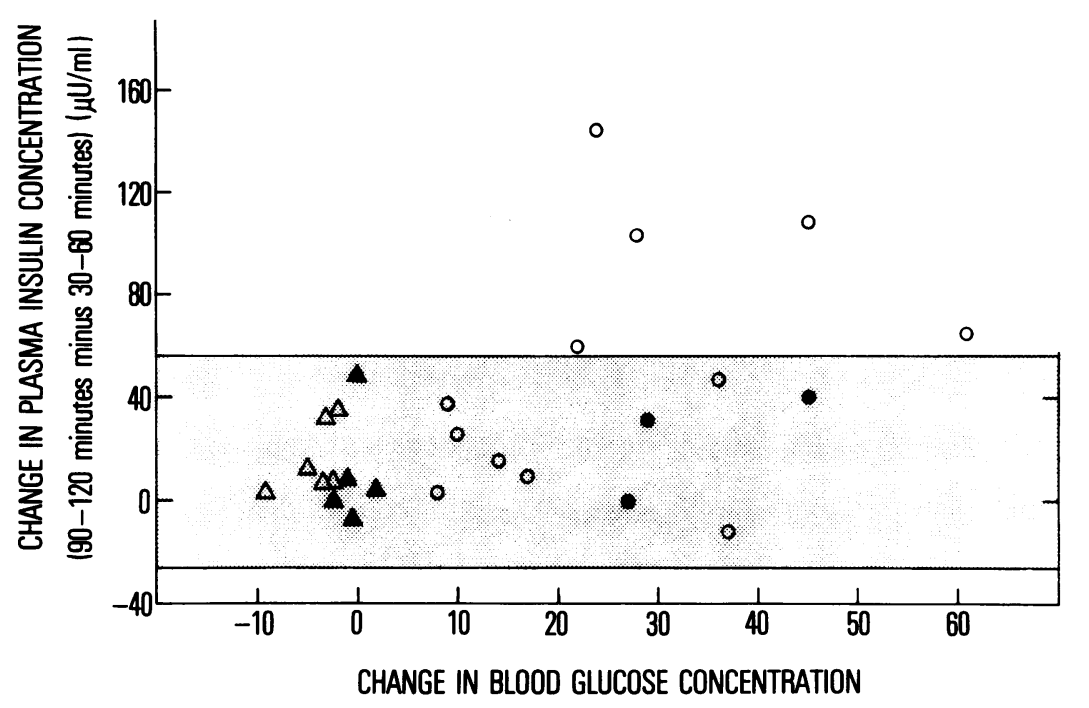

(90-120 minutes minus basal) $(\mathrm{mg} / \mathrm{dll}$

FIGURE 4 Hyperglycemic threshold for GIP effect on insulin secretion. All values are derived from insulin infusion studies. The closed symbols are studies in which oral glucose was not ingested and in which the blood glucose concentration was either maintained at the euglycemic level $(\Delta)$ or with hyperglycemia $(0)$. The shaded area represents the mean \pm 2 SD of the change in plasma insulin concentration in these studies. The open symbols are studies in which glucose was ingested at $60 \mathrm{~min}$ and either euglycemia $(\triangle)$ or hyperglycemia $(O)$ was maintained.

from 90 to $120 \mathrm{~min}$ ranging from 8 to $61 \mathrm{mg} / \mathrm{dl}$ above the basal level (Fig. 4).

Of the seven subjects whose plateau glucose concentration after oral glucose ranged from 22 to $61 \mathrm{mg} / \mathrm{dl}$ above basal, the 90-120-min IRI values were considerably higher than the 30-60-min value in five of the subjects and averaged $74 \pm 19.2 \mu \mathrm{U} / \mathrm{ml}$ higher for the entire group of seven $(P<0.01)$. However, the 90-120min IRI values in three subjects without glucose ingestion with plateaus of 27,29 , and $45 \mathrm{mg} / \mathrm{dl}$ above basal averaged only $24 \pm 12.6 \mu \mathrm{U} / \mathrm{ml}$ above the $30-60$ min value. To define further the threshold value of blood glucose at which GIP becomes an effective insulin secretagogue, five experiments were performed in which the plateau glucose concentration after oral glucose ranged from 9 to $18 \mathrm{mg} / \mathrm{dl}$ above the baseline. In this group, the 90-120-min IRI values averaged $23 \pm 8.4 \mu \mathrm{U} / \mathrm{ml}$ greater than the mean values at $30-60$ $\mathrm{min}$; this value is not significantly different from the increase in insulin which occurred at 90-120 min in the five euglycemic studies in which oral glucose was not given $(9 \pm 9 \mu \mathrm{U} / \mathrm{ml})$ or in the six euglycemic subjects who did receive oral glucose $(17 \pm 6 \mu \mathrm{U} / \mathrm{ml})$.

GIP responses (Table I, Group C) were assayed in 10 of the 12 subjects who were given an insulin infusion for $2 \mathrm{~h}$; this group received oral glucose at $1 \mathrm{~h}$ and hyperglycemia occurred during the 2nd h (see Methods). The mean basal value was the same as that of the six insulin infusion studies in which euglycemia was maintained. The GIP response to oral glucose was somewhat greater in the 10 subjects in whom mild or moderate hyperglycemia occurred, but this difference was not statistically significant.

All insulin infusion studies are summarized in Fig. 4. The shaded area represents the insulin range (mean \pm 2 SD) of those studies ( $n=8$, closed symbols) in which oral glucose was not administered. It can be seen that below a blood glucose elevation of $20 \mathrm{mg} / \mathrm{dl}$ above the basal level, insulin levels were not significantly augmented by GIP after oral glucose $(n=11$, open symbols). When the blood glucose concentration was elevated by more than $20 \mathrm{mg} / \mathrm{dl}$ above basal, five of the seven subjects who received oral glucose (open circles) showed a plasma insulin increase.

\section{DISCUSSION}

The search for the hormonal mediator of the socalled enteroinsular axis has long been the subject of investigation. In 1932, LaBarre (28) suggested that the name "incretin" be applied to that enteric hormone which augments glucose-stimulated insulin release. Although the investigation of the established gastrointestinal hormones cholecystokinin-pancreozymin, gastrin, and secretin, as well as other candidates has at times yielded suggestive support of their involvement (29-32), the identity of a single responsible hormone has remained unsettled. Physiological (endog- 
enous) release of the previously established hormones has not been clearly shown to be adequate to produce circulating levels at which insulin release can be demonstrated. Furthermore, when infused in amounts that do not exceed physiologic levels, they have not been shown to be insulinotropic.

Recently, evidence has begun to appear which suggests that the 43 amino acid polypeptide, GIP, may be the enteric mediator in the enteroinsular axis. GIP has been isolated from the small bowel and the gastric antrum (33), has been found in the duodenum and jejunum in highest concentration (22), and has been localized to a specific small intestinal cell type (34). Its release has been shown to be stimulated by oral glucose (10), oral fat (14), and by a mixed meal (21). Furthermore, infusion of purified GIP within a physiologic dose range has been shown to stimulate insulin release when administered with a concomitant infusion of glucose (9).

The present study confirms that oral glucose results in prompt and significant elevations in IR-GIP. The experimental protocols used in this study examine the effect of oral glucose administration on plasma GIP levels under three conditions (Table I): (A) in the presence of marked hyperglycemia and moderate endogenously-produced hyperinsulinemia; (B) in the presence of marked exogenously-produced hyperinsulinemia and euglycemia; and $(C)$ in the presence of marked (exogenous) hyperinsulinemia and mild or moderate hyperglycemia. We cannot examine the effect of oral glucose on plasma GIP and still maintain both basal glucose and basal insulin levels. The lowest GIP responses occurred in condition (A) and the highest responses occurred in condition (C). The GIP responses, judged either by the $90-120-\mathrm{min}$ levels or by the increment in the $90-120$-min level over the $0-60$-min level, are statistically significantly greater in condition (C) than (A), but (C) does not differ significantly from (B), nor does (B) differ significantly from (A). We cannot say from these studies alone whether marked hyperglycemia inhibits or marked hyperinsulinemia stimulates the gut cell response to oral glucose, but it is clear that hyperinsulinemia does not inhibit the response.

Other studies have shown that experimental situations that cause elevation of both serum glucose and insulin tend to depress the response of the gut cell to oral fat or to a mixed meal $(23,24,35,36)$. In two of the studies, the gut cell response to oral fat was studied in the presence and in the absence of an intravenous glucose infusion $(23,24)$; GIP concentrations were lower after IV glucose and its concomitant hyperinsulinemia in both studies.

In a third study (35), an intravenous bolus of insulin also diminished the gut cell response to triglyceride, but the altered GIP response did not occur un- til the serum insulin concentration had returned to its basal value at which time hypoglycemia and hyperglucagonemia were present. In the fourth study (36), a mixed test meal was administered to pancreatitis patients. The patients were divided into three groups on the basis of their insulin responses to the meal. The serum glucose levels varied inversely with the insulin responses. The group with intermediate insulin and glucose responses had a significantly greater GIP response than those with the lowest and the highest insulin and glucose responses. Our own results, in which the stimulus to GIP release was oral glucose rather than oral triglyceride or a mixed meal, show the lowest GIP response in the situation with marked hyperglycemia and only moderate hyperinsulinemia (Table I, [A]). There have been no studies reported in which, when oral glucose is the stimulus to the gut cell, hyperinsulinemia has been shown to have a suppressive effect on GIP release.

The time course of the rise in plasma insulin after oral glucose during constant hyperglycemia is seen to follow the time course of the rise in IR-GIP almost identically (Fig. 1). This time course can also be seen in Fig. 5 which may be considered as a dose-response curve. If the association of IR-GIP and IRI from 60 to $120 \mathrm{~min}$ is assumed to be a simple linear one, then the coefficient of correlation is computed to be 0.979 . However, the curve appears to have the characteristics of a sigmoid relationship; further

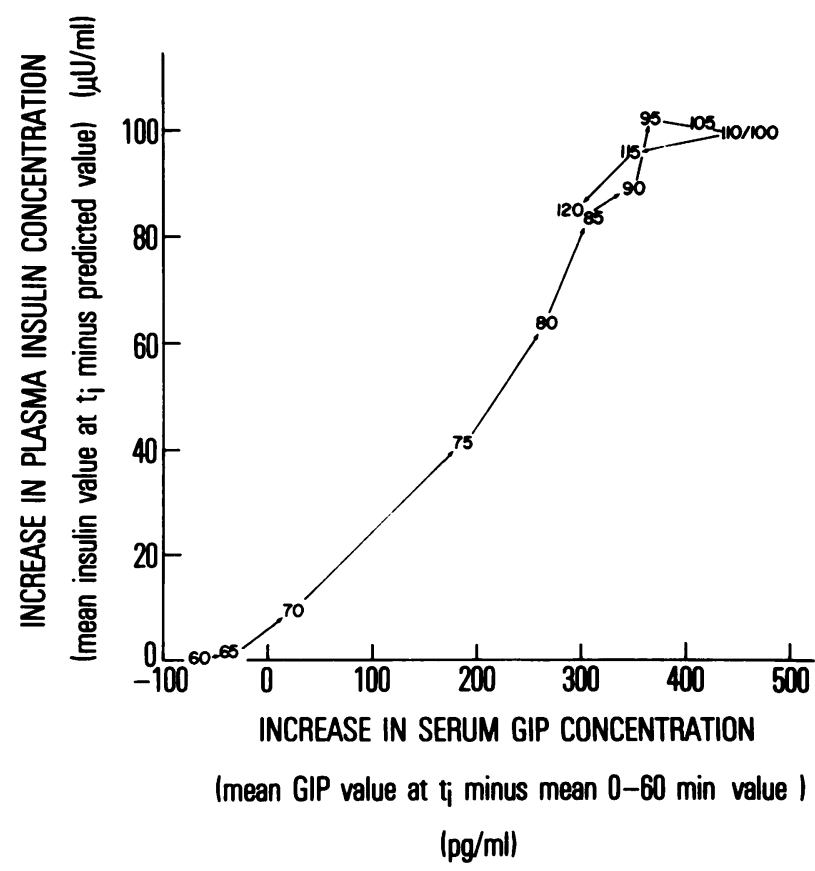

Figure 5 Dose-response relationship of GIP and insulin during hyperglycemic clamp. Values are shown for each 5-min sample $\left(t_{i}\right)$ after oral glucose at $60 \mathrm{~min}$. 
studies are required to define the association more definitively.

The finding that the insulinotropic effect of ingested glucose is absent during euglycemia is particularly intriguing in light of previous observations that fat ingestion, a potent stimulus to GIP release (14), is accompanied by either no insulin release $(24,37)$ or by a very small increase of about $4 \mu \mathrm{U} / \mathrm{ml}(15,23,38-40)$, unless hyperglycemia is present. On the other hand, an insulinotropic effect of GIP independent of hyperglycemia has been reported in the dog (41). However, the dose of GIP infused in this study produced serum GIP levels of $\sim 2,500-15,000 \mathrm{pg} / \mathrm{ml}$. The demonstration of the requirement for glucose infusion for exogenous GIP to be insulinotropic in man (9) and the in vitro findings of the lack of an insulinotropic effect at low glucose concentrations in an isolated islet preparation (42) and isolated perfused pancreas (43) complement findings of the current study in man, namely that endogenous GIP does not augment insulin release unless blood glucose levels are elevated by at least $20 \mathrm{mg} / \mathrm{dl}$. Teleologically, such a threshold mechanism would appear appropriate to prevent the release of a potentially harmful quantity of insulin at a time when insufficient substrate concentration is present.

These studies do not rule out the possibility that one or more other as yet unidentified gastrointestinal hormones play a role in the mediation of the gastrointestinal phase of insulin secretion after glucose ingestion or that autonomic nervous system influences may contribute to this effect. The glucose clamp studies do show that in intact man there is a link between serum-endogenous GIP and insulin levels that is consistent with a growing literature in which other types of preparations and experimental protocols have been employed. That GIP is, at a minimum, a major component among the physiological stimuli to insulin secretion now appears to be definite.

\section{ACKNOWLEDGMENTS}

The authors are grateful for the assistance of Dr. Gary S. Raizes in preparation of data for analysis. The excellent technical assistance of Ms. Mary E. Bannon, Ms. Faye Barrack, Ms. Jeanette Frost, Mr. Howard Baldwin, and Mr. Denis Muller is greatly appreciated. We thank also Ms. Helen Burns for excellent secretarial assistance and Ms. J. Carre, Ms. M. Scott, and Ms. J. Budries for expert nursing assistance during the studies.

The study was supported in part by a grant to Dr. J. C. Brown from the Medical Research Council of Canada.

\section{REFERENCES}

1. Moore, B., E. S. Edie, and J. H. Abram. 1906. On the treatment of diabetes mellitus by acid extract of duodenal mucous membrane. Biochem. J. 1: 28-38.

2. Berson, S. A., and R. S. Yalow. 1960. Immunoassay of endogenous plasma insulin in man. J. Clin. Invest. 39: 1157-1175.

3. McIntyre, N., C. C. Holdsworth, and D. S. Turner. 1964. New interpretation of oral glucose tolerance. Lancet. II: $20-21$.

4. Perley, M. J., and D. M. Kipnis. 1967. Plasma insulin responses to oral and intravenous glucose. Studies in normal and diabetic subjects. J. Clin. Invest. 46: 19541962.

5. Dupré, J., and J. C. Beck. 1966. Stimulation of release of insulin by an extract of intestinal mucosa. Diabetes. 15: 555-559.

6. Ohneda, A., E. Parada, A. M. Eisentraut, and R. H. Unger. 1968. Characterization of response of circulating glucagon to intraduodenal and intravenous administration of amino acids. J. Clin. Invest. 47: 2305-2322.

7. Rehfeld, J. F. 1972. Gastrointestinal hormones and insulin secretion. Scand. J. Gastroenterol. 7: 289-292.

8. Brown, J. C., V. Mutt, and R. A. Pederson. 1970. Further purification of a polypeptide demonstrating enterogastrone activity. J. Physiol. (Lond.). 209: 57-64.

9. Dupré, J., S. A. Ross, D. Watson, and J. C. Brown. 1973. Stimulation of insulin secretion by gastric inhibitory polypeptide in man. J. Clin. Endocrinol. Metab. 37: 826-828.

10. Cataland, S., S. E. Crockett, J. C. Brown, and E. L. Mazzaferri. 1974. Gastric inhibitory polypeptide (GIP) stimulation by oral glucose in man. J. Clin. Endocrinol. Metab. 39: 223-228.

11. Thomas, F. B., D. F. Shook, T. M. O'Dorisio, S. Cataland, H. S. Mekhjian, J. H. Caldwell, and E. L. Mazzaferri. 1977. Localization of gastric inhibitory polypeptide release by intestinal glucose perfusion in man. Gastroenterology. 72: 49-54.

12. Ross, S. A., J. C. Brown, and J. Dupré. 1977. Hypersecretion of gastric inhibitory polypeptide following oral glucose in diabetes mellitus. Diabetes. 26: 525-529.

13. Crockett, S. E., E. L. Mazzaferri, and S. Cataland. 1976. Gastric inhibitory polypeptide (GIP) in maturity-onset diabetes mellitus. Diabetes. 25: 931-935.

14. Brown, J. C. 1974. Gastric inhibitory polypeptide (GIP). In Endocrinology. 1973. Proceedings of the 4th International Symposium. S. Taylor, editor. William Heinemann Medical Books, Ltd., London. 276-284.

15. Falko, J. M., S. E. Crockett, S. Cataland, and E. L. Mazzaferri. 1975. Gastric inhibitory polypeptide (GIP) stimulated by fat ingestion in man. J. Clin. Endocrinol. Metab. 41: 260-265.

16. Andres, R., R. S. Swerdloff, T. Pozefsky, and D. Coleman. 1966. Manual feedback technique for the control of blood glucose concentration. In Automation in Analytical Chemistry (Technicon Symposia). L. T. Skeggs, Jr., editor. Mediad, Inc., New York. 486-491.

17. Sherwin, R. S., K. J. Kramer, J. D. Tobin, P. A. Insel, J. E. Liljenquist, M. Berman, and R. Andres. 1974. A model of the kinetics of insulin in man. J. Clin. Invest. 53: $1481-1492$

18. Andres, R. 1971. Aging and diabetes. Med. Clin. N. Am. 55: 835-846.

19. McGuire, E. A. H., J. H. Helderman, J. D. Tobin, R. Andres, and M. Berman. 1976. Effects of arterial versus venous glucose sampling on the analysis of glucose kinetics in man. J. Appl. Physiol. 41: 565-573.

20. Morgan, C. R., and A. Lazarow. 1963. Immunoassay of insulin: two antibody system. Plasma insulin levels in normal, subdiabetic, and diabetic rats. Diabetes. 12: $115-126$.

21. Kuzio, M., J. R. Dryburgh, K. M. Malloy, and J. C. Brown. 1974. Radioimmunoassay for gastric inhibitory polypeptide. Gastroenterology. 66: 357-364. 
22. O'Dorisio, T. M., S. Cataland, M. Stevenson, and E. Mazzaferri. 1976. Gastric inhibitory polypeptide (GIP): Intestinal distribution and stimulation by amino acids and medium-chain triglycerides. Am. J. Dig. Dis. 21: 761-765.

23. Crockett, S. E., S. Cataland, J. M. Falko, and E. L. Mazzaferri. 1976. The insulinotropic effect of endogenous gastric inhibitory polypeptide in normal subjects. J. Clin. Endocrinol. Metab. 42: 1098-1103.

24. Cleator, I. G. M., and R. H. Gourlay. 1975. Release of immunoreactive gastric inhibitory polypeptide (IR-GIP) by oral ingestion of food substances. Am. J. Surg. 130: $128-135$.

25. Botha, J. L., A. I. Vinik, and J. C. Brown. 1976. Gastric inhibitory polypeptide (GIP) in chronic pancreatitis. $J$. Clin. Endocrinol. Metab. 42: 791-797.

26. Creutzfeldt, W., R. Ebert, R. Arnold, H. Frerichs, and J. C. Brown. 1976. Gastric inhibitory polypeptide (GIP) gastrin and insulin; response to test meal in coeliac disease and after duodeno-pancreatectomy. Diabetologia. 12: 279-286.

27. Ebert, R., R. Arnold, and W. Creutzfeldt. 1977. Lowering of fasting and food stimulated serum immunoreactive gastric inhibitory polypeptide (GIP) by glucagon. Gut. 18: 121-127.

28. LaBarre, J. 1932. Sur les possibilites d'un traitement du diabete par l'incretine. Bull. Acad. R. Med. Belg. 12 : 620-634.

29. Chisholm, D. J., J. D. Young, and L. Lazarus. 1969. The gastrointestinal stimulus to insulin release. I. Secretin. J. Clin. Invest. 48: 1453-1460.

30. Turner, D. S., A. Shabban, L. Etheridge, and V. Marks. 1973. The effects of an intestinal polypeptide fraction on insulin release in the rat, in vivo and in vitro. Endocrinology. 93: 1323-1328.

31. Unger, R. H., H. Ketterer, J. Dupré, and A. M. Eisentraut. 1967. The effects of secretin, pancreozymin and gastrin on insulin and glucagon secretion in anesthesized dogs. J. Clin. Invest. 46: 630-645.

32. Unger, R. H., A. Ohneda, I. Valverdi, A. M. Eisentraut, and J. Exton. 1968. Characterization of the responses of circulating glucagon-like immunoreactivity to intraduo- denal and intravenous administration of glucose. J. Clin. Invest. 47: 48-65.

33. Brown, J. C., R. A. Pederson, J. E. Jorpes, and V. Mutt. 1969. Preparation of highly active enterogastrone. Can. J. Physiol. Pharmacol. 47: 113-114.

34. Buffa, R., J. M. Polak, A. G. E. Pearse, E. Solcia, L. Grimelius, and C. Capella. 1975. Identification of intestinal cell storing gastric inhibitory peptide. Histochemistry. 43: 249-255.

35. Brown, J. C., J. R. Dryburgh, S. A. Ross, and J. Dupre. 1975. Identification and actions of gastric inhibitory polypeptide. Recent. Prog. Horm. Res. 31: 487-531.

36. Ebert, R., W. Creutzfeldt, J. C. Brown, H. Frerichs, and R. Arnold. 1976. Response of gastric inhibitory polypeptide (GIP) to test meal in chronic pancreatitisrelationship to endocrine and exocrine insufficiency. Diabetologia. 12: 609-612.

37. Böttger, I., R. Dobbs, G. R. Faloona, and R. H. Unger. 1973. The effects of triglyceride absorption upon glucagon, insulin, and gut glucagon-like immunoreactivity. $J$. Clin. Invest. 52: 2532-2541.

38. Pi-Sunyer, F. X., S. A. Hashim, and T. B. Van Itallie. 1969. Insulin and ketone responses to ingestion of medium and long-chain triglycerides in man. Diabetes. 18: $96-100$.

39. Carroll, K. F., and P. J. Nestel. 1972. Effect of longchain triglyceride on human insulin secretion. Diabetes. 21: $923-929$.

40. Dobbs, R., G. R. Faloona, and R. H. Unger. 1975. Effect of intravenously administered glucose on glucagon and insulin secretion during fat absorption. Metab. Clin. Exp. 24: 69-75.

41. Pederson, R. A., H. E. Schubert, and J. C. Brown. 1975. The insulinotropic action of gastric inhibitory polypeptide. Can. J. Physiol. Pharmacol. 53: 217-223.

42. Schauder, P., J. C. Brown, H. Frerichs, and W. Creutzfeldt. 1975. Gastric inhibitory polypeptide: effect on glucose-induced insulin release from isolated rat pancreatic islets in vitro. Diabetologia. 11: 483-484.

43. Pederson, R. A., and J. C. Brown. 1976. The insulinotropic action of gastric inhibitory polypeptide in the perfused isolated rat pancreas. Endocrinology. 99: 782-785. 